\title{
Chế tạo và khảo sát khả năng tăng cường tín hiệu Raman của đế Silic cấu trúc kim tự tháp/nano bạc
}

\author{
Đậu Trần Ánh Nguyệt ${ }^{1,2^{*}}$, Văn Võ Kim Hiếu ${ }^{1,2}$ \\ Trân Thị Thanh Vân ${ }^{1,2}$, Huỳnh Nguyễn Thanh Luận ${ }^{1,2^{*}}$ \\ ${ }^{1}$ Khoa Khoa học và Công nghệ vật liệu, Trường Đại học Khoa học tự nhiên, Đại học Quốc gia \\ thành phố Hồ Chí Minh, Việt Nam \\ ${ }^{2} Đ a ̣ i$ học Quốc gia thành phố Hồ Chí Minh, Việt Nam
}

(Ngày đến tòa soạn: 03/11/2020 ; Ngày chấp nhận đăng: 08/02/2021)

\section{Tóm tắt}

Đế Silic có cấu trúc kim tự tháp được chế tạo thành công bằng phương pháp ăn mòn hóa học. Mật độ kim tự tháp trên bề mặt đế dày, kích thước trung bình khoảng $1-3 \mu \mathrm{m}$ với các thông số chế tạo tối ưu như nhiệt độ ăn mòn ở $70^{\circ} \mathrm{C}$, thời gian ăn mòn là 5 phút, nông độ dung dịch $\mathrm{KOH}$ là $3 \mathrm{M}$ và nồng độ dung dịch isopropyl alcohol là $1 \mathrm{M}$. Sau đó, lớp nano bạc (bề dày $20 \mathrm{~nm}$ ) được phủ lên bề mặt đế Silic cấu trúc kim tự tháp bằng phương pháp phún xạ để tăng cường tín hiệu tán xạ Raman bề mặt (SERS). Kết quả cho thấy, đế Silic cấu trúc kim tự tháp/ nano Ag cho hiệu ứng tăng cường tín hiệu Raman phát hiện được chất màu Rhoamine $6 \mathrm{G}$ trong thực phẩm ở nồng độ thấp $\left(10^{-6} \mathrm{M}\right)$ và có hệ số tăng cường là $9,7 \times 10^{2}$.

Tư khóa: Ag@PSi, đế Silic, PSi, Raman, SERS.

\section{1. ĐẶT VẤN ĐỀ}

An toàn vệ sinh thực phẩm đang là vấn đề thiết yếu được cả xã hội quan tâm. Có nhiều phương pháp khác nhau đã được sử dụng trong việc đánh giá hàm lượng các chất trong các mẫu thực phẩm, gồm có phương pháp quang phổ hấp thụ nguyên tử ngọn lửa (AAS), phương pháp quang phổ UV-Vis, phương pháp phân tích phổ hông ngoại (FT-IR),... Trong đó, phương pháp phân tích quang phổ Raman đã và đang trở thành một công cụ quan trọng nhờ những thông tin về dao động phân tử, được xem như dấu vân tay của các phân tử mà nó có thể cung cấp, dựa trên cơ sở các thông tin về tần số dao động phân tử. Tuy nhiên, hạn chế của phương pháp này là tín hiệu phổ yếu và khó phát hiện khi các mẫu có nồng độ cần phân tích thấp. Từ đó, hiệu ứng tán xạ Raman tăng cường bê mặt (SERS) ra đời và đây được xem như phương pháp quang phổ mới khắc phục những hạn chế trên. Phương pháp SERS giúp cho tín hiệu tán xạ được tăng cường lên nhiêu lần $\left(10^{6}-10^{14}\right.$ lần $)$ do phương pháp này có độ nhạy rất cao. Nguyên lý của phương pháp là sử dụng các loại đế có thể cộng hưởng tần số với ánh sáng laser kích thích, từ đó làm tăng cường độ tín hiệu tán xạ của mẫu cần phân tích [1-5].

Đế Silic cấu trúc kim tự tháp (3D Si) có diện tích tán xạ lớn và ánh sáng laser tới có thể tạo ra dao động hiệu quả trong các thành của kim tự tháp, nhờ đó tăng cường được độ nhạy của đế SERS. Ngoài ra, với cấu trúc các dãy kim tự tháp sắp xếp có trật tự và riêng biệt nhau, nhờ đó bề mặt đế đông nhất. Nhờ các ưu điểm nổi bật này, các nhà khoa học đã sử dụng cấu trúc $3 \mathrm{D}$ Si kết hợp với các hạt nano bạc để tạo ra các đế SERS có hệ số tăng cường $(\mathrm{EF})>10^{6}$, độ bền và

*Điện thoại: 0907786675

*Điện thoai: 0919596869
Email: dtanguyet@hcmus.edu.vn

Email:hntluan@hcmus.edu.vn 
tuổi thọ cao [1-2, 5-8]. Trong nghiên cứu này, đế Silic cấu trúc kim tự tháp được chế tạo bằng phương pháp ăn mòn ướt, bề mặt đế được phủ một lớp nano Ag bằng phương pháp phún xạ nhằm mục đích tăng cường tín hiệu Raman trong việc phát hiện chất màu Rhodamine $6 \mathrm{G}$, một chất màu được trộn trái phép trong thực phẩm [6-11]. Trong quá trình chế biến thực phẩm, để tạo cho thực phẩm màu sắc đẹp, bắt mắt, người ta sử dụng phẩm màu công nghiệp. Phẩm màu công nghiệp nói chung, Rhodamine $6 \mathrm{G}$ nói riêng đều độc hại, bị cấm sử dụng trong thực phẩm vì khó phân huỷ. Tùy từng cơ thể mà ảnh hưởng đến gan, thận hoặc tồn dư lâu ngày gây độc hại đến cơ thể con người, đặc biệt có thể gây ung thư. Phẩm màu thực phẩm và tự nhiên có độ bền kém hơn, lại đắt hơn phẩm màu công nghiệp. Vì vậy việc nghiên cứu xác định hàm lượng của các Rhodamine $6 \mathrm{G}$, một thành phần của phẩm nhuộm trong thực phẩm là vấn đề cần thiết đối với sức khoẻ cộng đông.

\section{VẠT LIÊUU VÀ PHƯƠNG PHÁP NGHIÊN CƯU}

\subsection{Vật liệu}

Các vật liệu được sử dụng trong nghiên cứu gồm: đế Silic của Hàn Quốc; aceton $\left(\mathrm{CH}_{3} \mathrm{COCH}_{3} 99 \%\right)$ của Ấn Độ; isopropyl alcohol (IPA 99,8\%), kali hydroxide $(\mathrm{KOH})$ và acid chlohydric $(\mathrm{HCl} 37 \%)$ của Merck - Đức; hydroperoxide $\left(\mathrm{H}_{2} \mathrm{O}_{2}\right)$, acid fluorohydric ( $\left.\mathrm{HF} 43 \%\right)$ và methanol $\left(\mathrm{CH}_{3} \mathrm{OH} 99 \%\right)$ của Trung Quốc; rhodamine 6G (R6G 99\%) của Sigma và một số hóa chất khác trong phòng thí nghiệm.

\subsection{Quy trình tạo đế Silic cấu trúc kim tự tháp/nano bạc}

\subsubsection{Tạo đế Silic cấu trúc kim tự tháp (PSi) bằng phương pháp ăn mòn hóa học}

Đầu tiên, chuẩn bị đế Silic đơn tinh thể loại p, định hướng (100) và kích thước $1 \mathrm{~cm} \times 1 \mathrm{~cm}$. Làm sạch đế lần lượt với acetone, IPA và nước khử ion (DI) trong bể siêu âm mỗi lần 5 phút, ở $500^{\circ} \mathrm{C}$. Sau đó, ngâm lần lượt trong các dung dịch: dung dịch $\mathrm{HCl}: \mathrm{H}_{2} \mathrm{O}_{2}: \mathrm{H}_{2} \mathrm{O}(1: 1: 8, \mathrm{v} / \mathrm{v} / \mathrm{v})$, dung dịch $\mathrm{HF} 0,2 \%$, dung dịch IPA và $\mathrm{DI}$ khoảng 10 giây rồi làm khô đế bằng khí $\mathrm{N}_{2}$. Tiếp theo, ăn mòn đế Silic trong dung dịch $(\mathrm{KOH}+\mathrm{IPA})$ ở nhiệt độ và thời gian thích hợp. Cuối cùng, rửa lại đế với $\mathrm{DI}$ và làm khô bằng khí $\mathrm{N}_{2}$.

\subsubsection{Tạo lớp phủ nano bạc trên đế Silic cấu trúc kim tự tháp bằng phương pháp phún xạ}

Phún xạ màng bạc có độ dày $20 \mathrm{~nm}$ lên đế $P S i$ và đế Silic với dòng điện 1 chiều $15 \mathrm{~mA}$, lưu lượng khí argon là $5 \mathrm{sccm}$ và tốc độ phún xạ là $0,2 \AA / \mathrm{s}$, thời gian phún xạ là 7 phút.

\subsection{Phương pháp phân tích}

Phân tích cấu trúc tinh thể bằng giản đồ nhiễu xạ tia $\mathrm{X}(\mathrm{XRD})$. Mẫu được ghi trên máy SIEMENS D5000 (Bruker, Đức) với thế $40 \mathrm{kV}$, dòng $40 \mathrm{~mA}$. Khảo sát hình thái bề mặt bằng kính hiển vi điện tử quét FESEM S4800 (Hitachi, Nhật) với thế gia tốc $10 \mathrm{kV}$.

Phân tích phổ tán xạ Raman tăng cường bề mặt (SERS) được thực hiện trên hệ LABRAM HR EVOLUTION (Horaba, Nhật Bản); chất phân tích là chất màu Rhodamine (R6G) với công thức phân tử là $\mathrm{C}_{18} \mathrm{H}_{31} \mathrm{~N}_{2} \mathrm{O}_{3} \mathrm{Cl}$.

\section{KẾT QUẢ VÀ BÀN LUẬN}

\subsection{Khảo sát ảnh hưởng các thông số chế tạo lên cấu trúc kim tự tháp}

Trong nghiên cứu này, ảnh hưởng của các thông số chế tạo như nhiệt độ ăn mòn, thời gian 
ăn mòn, nông độ dung dịch $\mathrm{KOH}$ và nồng độ dung dịch IPA được khảo sát với quy ước tên mẫu là PSi_nhiệt độ_thời gian_nồng độ $\mathrm{KOH}$ _nồng độ IPA (ví dụ: mẫu PSi_70_5_3_1 nghĩa là mẫu được chế tạo ở nhiệt độ ăn mòn là $70^{\circ} \mathrm{C}$, thời gian ăn mòn là 5 phút, nổng độ dung dịch $\mathrm{KOH}$ là $3 \mathrm{M}$ và nồng độ dung dịch IPA là $1 \mathrm{M}$ ).

\subsubsection{Khảo sát nhiẹt độ ăn mòn}

Các mẫu PSi trong cùng điều kiện thí nghiệm như nhau, lần lượt thay đổi nhiệt độ ăn mòn từ $50^{\circ} \mathrm{C}$ đến $80^{\circ} \mathrm{C}$. Ảnh kính hiển vi quang học $(\mathrm{OM})$ của các mẫu PSi_50, PSi_60, PSi_70 và PSi_80 (Hình 1) cho thấy nhiệt độ ăn mòn càng tăng thì mật độ kim tự tháp hình thành trên đế càng nhiều, kích thước kim tự tháp càng lớn (mẫu PSi_50 có kích thước khoảng $1 \mu \mathrm{m}$, mẫu PSi_60 có kích thước khoảng 1 - $3 \mu \mathrm{m}$, mẫu PSi-70 có kích thước khoảng $3 \mu \mathrm{m}$ và mẫu PSi_80 có kích thước khoảng $5-6 \mu \mathrm{m})$. Tuy nhiên, một số kim tự tháp của mẫu PSi_80 có đỉnh chóp bị bầu đi, bởi vì nhiệt độ quá lớn sẽ phá hủy cấu trúc của kim tự tháp. Do đó, để đảm bảo mật độ, kích thước và hình dạng của kim tự tháp trên đế thì mẫu PSi_70 ở nhiệt độ ăn mòn $70^{\circ} \mathrm{C}$ đã được lựa chọn.

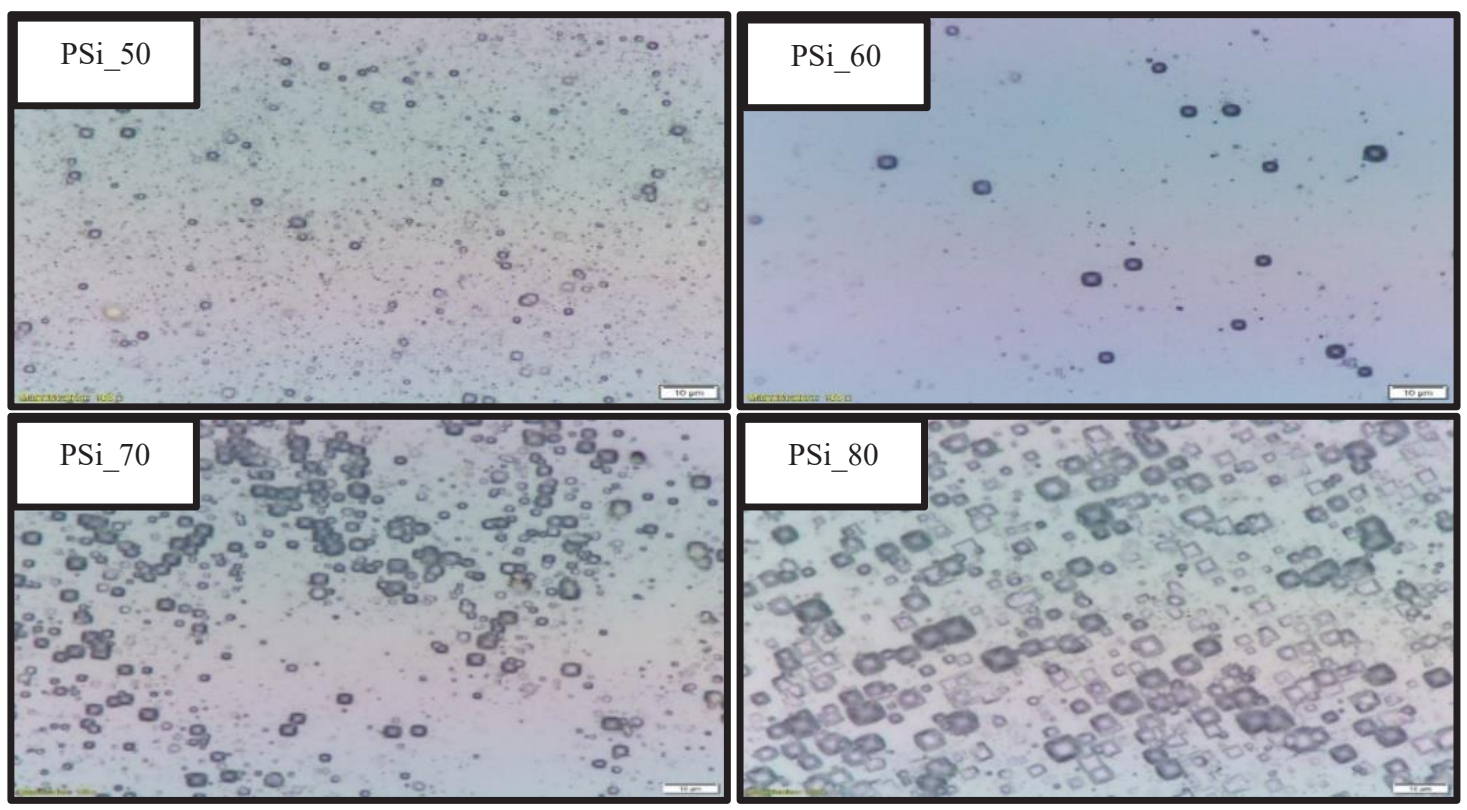

Hình 1. Ảnh OM của mẫu PSi_50,PSi_60,PSi_70 và PSi_80 ở thang do $10 \mu \mathrm{m}$

\subsubsection{Khảo sát thời gian ăn mòn}

Các mẫu PSi_70 (nhiệt độ ăn mòn ở $70^{\circ} \mathrm{C}$ ) trong cùng điều kiện thí nghiệm như nhau, lần lượt thay đổi thời gian ăn mòn từ 1 phút đến 15 phút. Ảnh OM của các mẫu PSi_70_1, PSi_70_2, PSi_70_3, PSi_70_4, PSi_70_5, PSi_70_6, PSi_70_10, PSi_70_15 tương ứng với thời gian ăn mòn lần lượt là 1 phút, 2 phút, 3 phút, 4 phút, 5 phút, 6 phút, 10 phút và 15 phút (Hình 2 ) cho thấy, thời gian ăn mòn ảnh hưởng đến kích thước, hình dạng và mật độ của kim tự tháp trên đế. Với thời gian ăn mòn từ 1 phút đến 4 phút, kích thước kim tự tháp chưa đông đều (khoảng $1-2 \mu \mathrm{m})$, mật độ ít. Với thời gian ăn mòn từ 6 phút đến 15 phút, kích thước kim tự tháp tăng dần nhưng mật độ giảm dần. Tuy nhiên, đối với mẫu PSi_70_5 tương ứng với thời gian ăn mòn là 5 phút, kích thước trung bình của các kim tự tháp tương đối đông đều (khoảng $2 \mu \mathrm{m}$ ), mật độ khá dày đặc. Như vậy, chúng tôi chọn mẫu PSi_70_5 là tối ưu. 


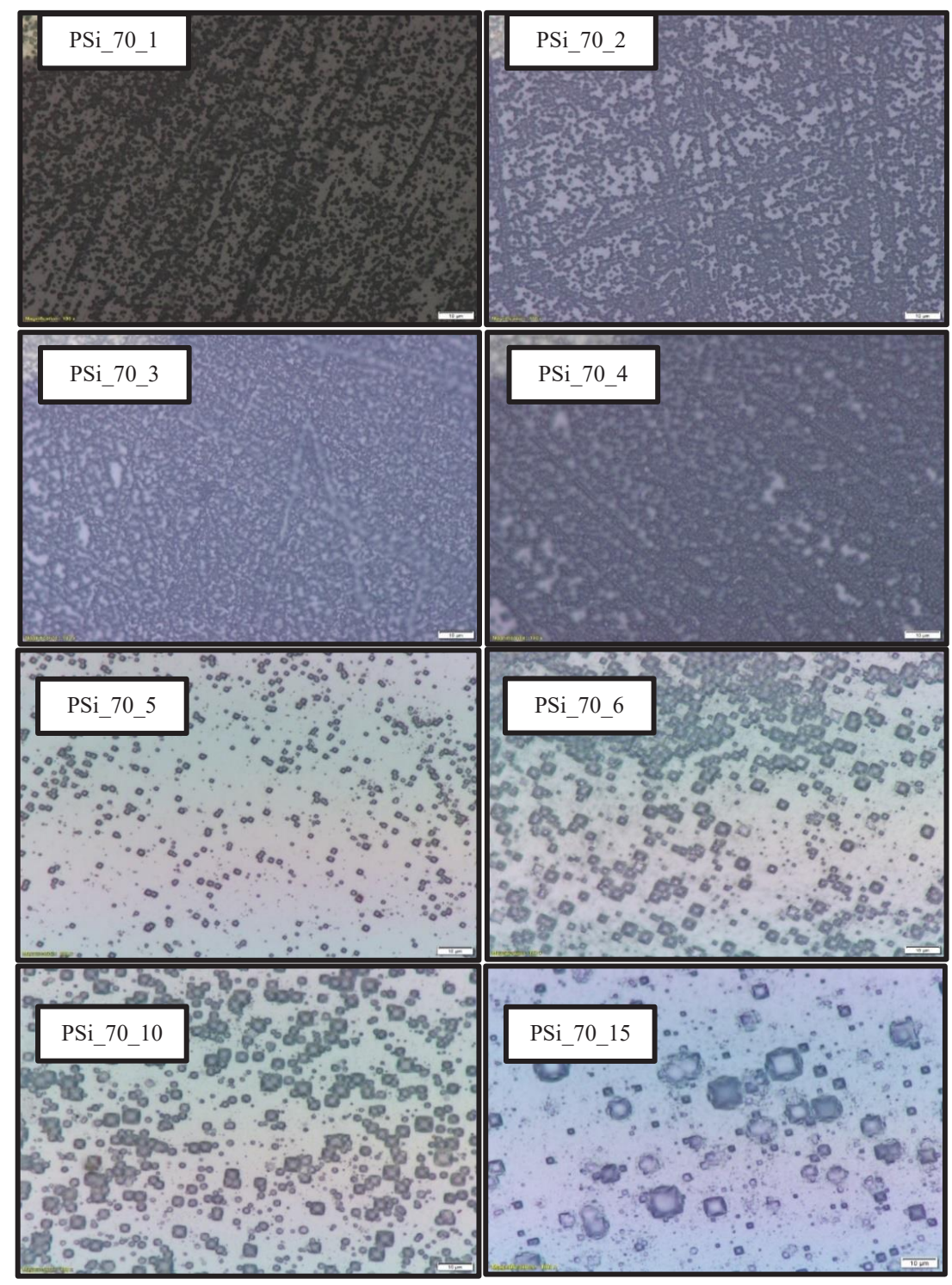

Hình 2. Ảnh OM của các mẫu Psi_70 với thời gian ăn mòn khác nhau ở thang đo $10 \mu \mathrm{m}$

\subsubsection{Khảo sát nông độ dung dịch $\mathrm{KOH}$}

Các mẫu PSi_70_5 (nhiệt độ ăn mòn ở 70 ${ }^{\circ} \mathrm{C}$, thời gian ăn mòn là 5 phút) lần lượt thay đổi nông độ dung dịch $\mathrm{KOH}$ là $1 \mathrm{M}, 2 \mathrm{M}, 3 \mathrm{M}, 7 \mathrm{M}$ và $10 \mathrm{M}$. Ảnh OM của các mẫu PSi_70_5_1, PSi_70_5_2, PSi_70_5_3, PSi_70_5_5, PSi_70_5_7 và PSi_70_5_10 tương ứng lần lượt với nông độ dung dịch $\mathrm{KOH} 1 \mathrm{M}, 2 \mathrm{M}, 3 \mathrm{M}, 5 \mathrm{M}, 7 \mathrm{M}$ và $10 \mathrm{M}$ (Hình 3) cho thấy, nông dộ dung dịch $\mathrm{KOH}$ ảnh hưởng đến tốc độ ăn mòn, mật độ và kích thước của kim tự tháp và tốc độ ăn mòn. Đối với nông độ dung dịch $\mathrm{KOH} 1 \mathrm{M}$ và $2 \mathrm{M}$, mật độ các kim tự tháp ít là do nông độ dung dịch $\mathrm{KOH}$ thấp, không đủ để xảy ra phản ứng ở tất cả các vị trí. Đối với nồng độ dung dịch $\mathrm{KOH} 5 \mathrm{M}, 7 \mathrm{M}$ và $10 \mathrm{M}$ thì các kim tự tháp có kích thước lớn, không đông đều, một số kim tự tháp bị mất đi đỉnh nhọn, chỉ còn lại phần chân đế và mật độ ít là do nồng độ dung dịch quá cao nên tốc độ ăn mòn nhanh dẫn đến phá hủy cấu trúc kim tự tháp [12]. Tuy nhiên, đối với nồng độ dung dịch $\mathrm{KOH}$ $3 \mathrm{M}$ thì kích thước kim tự tháp tương đối đông đều, mật độ dày đặc. Do đó, mẫu PSi_70_5_3 tương ứng nông độ dung dịch $\mathrm{KOH} 3 \mathrm{M}$ là tối ưu nhất. 


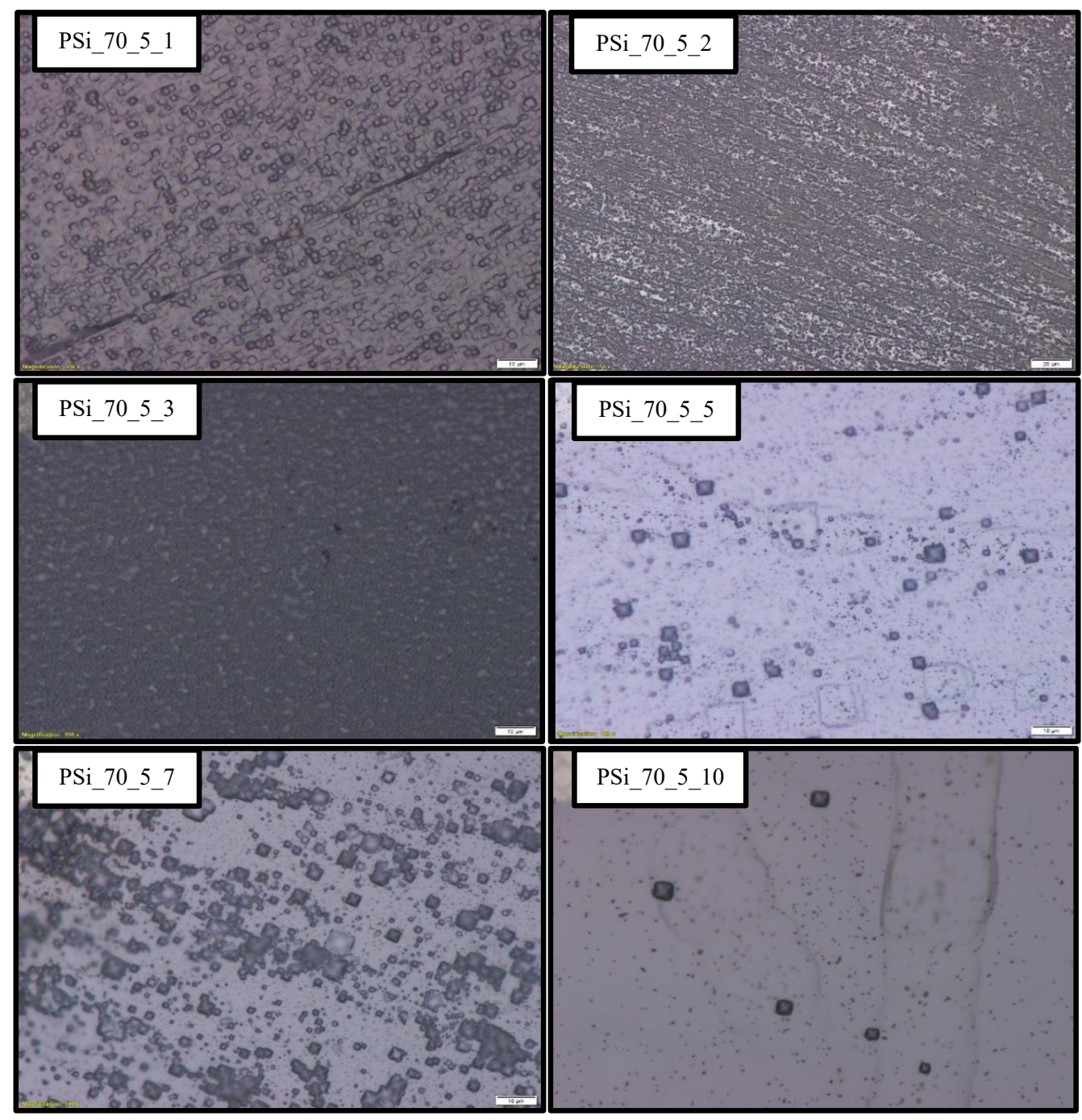

Hình 3. Ảnh OM của các mẫu PSi_70_5 với nông độ dung dịch $\mathrm{KOH}$ khác nhau ở thang do $10 \mu \mathrm{m}$

\subsubsection{Khảo sát nồng độ dung dịch IPA}

Các mẫu PSi_70_5_3 (ứng với nhiệt độ ăn mòn ở $70^{\circ} \mathrm{C}$, thời gian ăn mòn là 5 phút, nồng độ dung dịch $\mathrm{KOH}$ là $3 \mathrm{M}$ ) được khảo sát cấu trúc bằng cách thay đổi nồng độ dung dịch IPA là $0,5 \mathrm{M} ; 1 \mathrm{M} ; 1,5 \mathrm{M}$ và $2 \mathrm{M}$. Dung dịch IPA không tham gia vào quá trình ăn mòn nhưng nó ảnh hưởng mạnh đến kết quả ăn mòn, nó được coi là một "chất phụ gia" trong dung dịch ăn mòn. Độ gồ ghể của bề mặt phụ thuộc vào nông độ dung dịch IPA bởi vì nó có thể cải thiện độ ẩm của bề mặt Si giúp các ion $\mathrm{OH}$ - tương tác dễ dàng với bề mặt, đông thời hỗ trợ quá trình ăn mòn theo hướng của tinh thể và kiểm soát tốc độ ăn mòn bằng cách ngăn chặn phản ứng nổ giữa bề mặt $\mathrm{Si}$ và các ion $\mathrm{OH}-[13-14]$. Ảnh OM của các mẫu PSi_70_5_3_05, PSi_70_5_3_1, PSi_70_5_3_15 và PSi_70_5_3_2 (Hình 4) cho thấy nông độ dung dịch IPA ảnh hưởng đến cấu trúc và mật độ kim tự tháp trên bề mặt đế. Đối với mẫu có nồng độ dung dịch IPA là $0,5 \mathrm{M}$ và $1 \mathrm{M}$ thì mật độ kim tự tháp xuất hiện dày đặc. Đối với mẫu có nồng độ dung dịch IPA là $1,5 \mathrm{M}$ và $2 \mathrm{M}$ thì mật độ kim tự tháp giảm. Điều này là do nông độ dung dịch IPA quá cao nên tốc độ ăn mòn rất nhanh làm cho các kim tự tháp bị ăn mòn dần, dẫn đến mật độ kim tự tháp trên bề mặt đế giảm. 


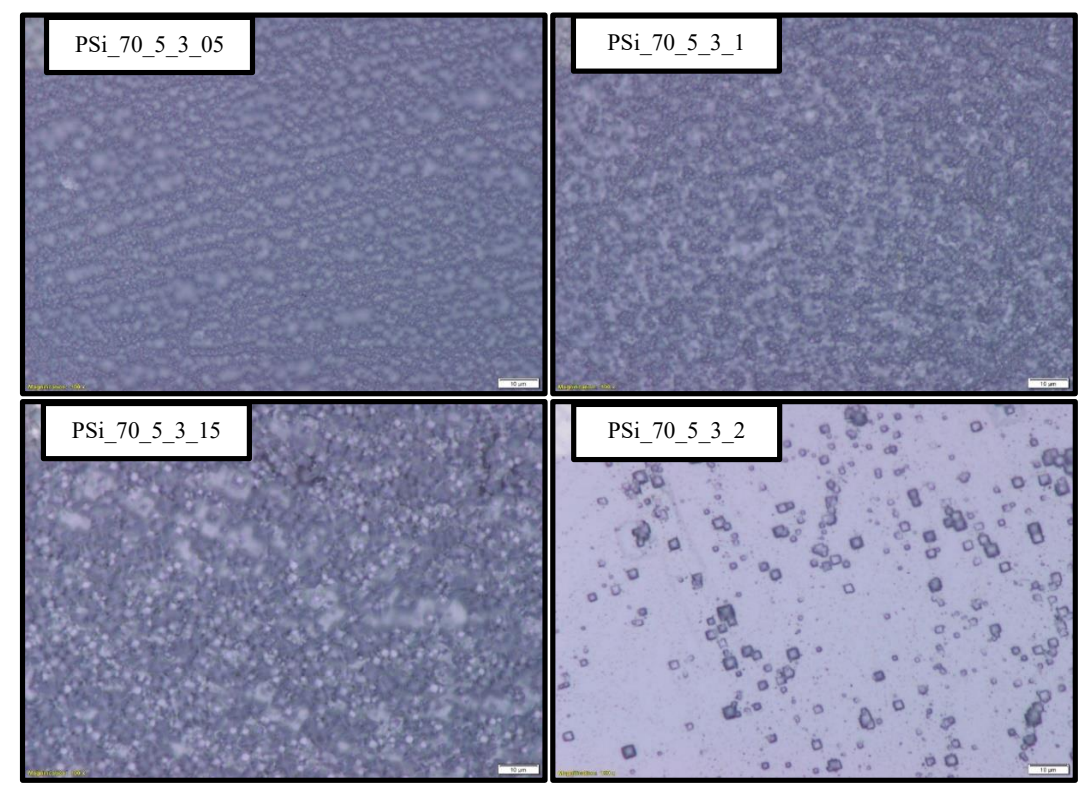

Hình 4. Ảnh OM của các mẫu PSi_70_5_3 với nông độ dung dịch IPA khác nhau ở thang do $10 \mu \mathrm{m}$

Bên cạnh đó, kết quả ảnh SEM của mẫu PSi_70_5_3_05 tương ứng với nồng độ dung dịch IPA là $0,5 \mathrm{M}$ (Hình 5) thu được các kim tự tháp có đỉnh nhọn, kích thước khoảng 1 - $3 \mu \mathrm{m}$, mật độ kim tự tháp dày và nằm sát nhau. Mẫu PSi_70_5_3_1 tương ứng với nông độ dung dịch IPA là $1 \mathrm{M}$ (Hình 5) các kim tự tháp thu được cũng có các đỉnh nhọn, mật độ dày và nằm sát nhau, nhưng kích thước kim tự tháp nhỏ hơn so với mẫu PSi_70_5_3_05 (khoảng $1-2 \mu \mathrm{m}$ ). Mẫu PSi_70_5_3_15 tương ứng với nông độ dung dịch IPA là 1,5 M (Hình 5) thì kim tự tháp thu được có mật độ dày, kích thước khoảng $2-5 \mu \mathrm{m}$. Tuy nhiên vì tốc độ ăn mòn nhanh nên các kim tự tháp bị ăn mòn dần, có xu hướng bị dẹt đi, không giữ được hình dạng khối chóp. Như vậy, nồng độ dung dịch IPA ảnh hưởng đến tốc độ ăn mòn, kích thước và mật độ kim tự tháp trên đế. Tuy nhiên, nếu nồng độ dung dịch IPA quá cao so với mức bão hòa thì tốc độ ăn mòn sẽ nhanh dẫn đến phá hủy cấu trúc kim tự tháp, làm thay đổi hình thái khối chóp; nếu nồng độ dung dịch IPA quá thấp chưa đạt đến mức bão hòa thì dung dịch ăn mòn sẽ không tiếp xúc được với bề mặt đế để thực hiện phản ứng giữa Si với các ion $\mathrm{OH}-$.
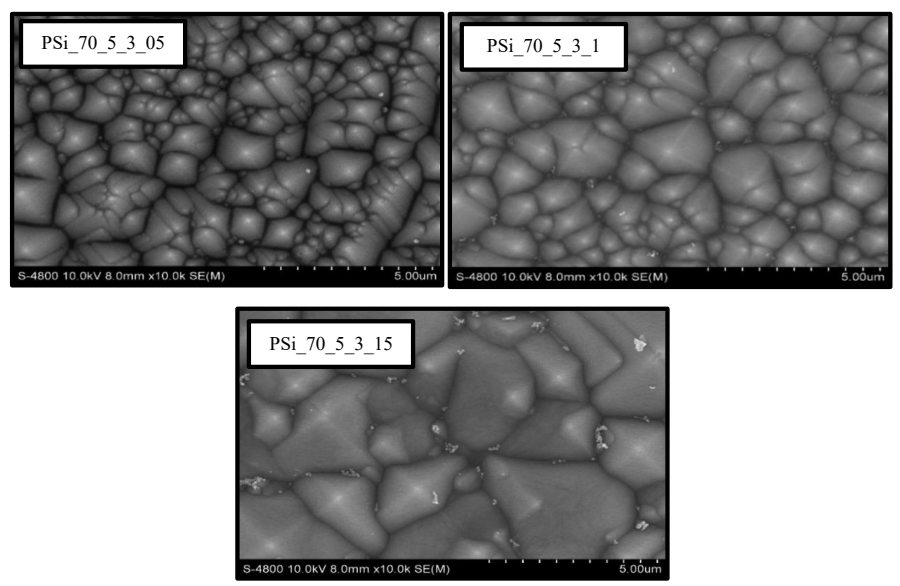

Hình 5. Ảnh SEM của mẫu PSi_70_5_3_15. 
Từ các phân tích ảnh hưởng của nông độ dung dịch $\mathrm{KOH}$ và dung dịch IPA có thể thấy rằng với nồng độ dung dịch $\mathrm{KOH}$ nhất định cần cho quá trình ăn mòn thì cần một lượng dung dịch IPA tương ứng để bảo đảm dung dịch ăn mòn đạt mức bão hòa, khi đó sẽ đảm bảo được các yếu tố mật độ, kích thước và hình thái của các kim tự tháp. Từ kết quả khảo sát các yếu tố ở trên, chúng tôi nhận thấy mẫu PSi_70_5_3_1 (nhiệt độ ăn mòn ở 70 C, thời gian ăn mòn là 5 phút, nồng độ dung dịch $\mathrm{KOH}$ là $3 \mathrm{M}$ và nông độ dung dịch IPA là $1 \mathrm{M}$ ) đáp ứng được các mục tiêu đặt ra về hình thái, mật độ và kích thước. Vì vậy, nhóm nghiên cứu tiếp tục sử dụng mẫu này để phủ các hạt nano bạc.

\subsection{Khảo sát cấu trúc của đế kim tự tháp/nano bạc bằng phương pháp phún xạ}

Ảnh SEM của mẫu PSi_70_5_3_1 (ứng với nhiệt độ ăn mòn ở 70 C, thời gian ăn mòn là 5 phút, nồng độ dung dịch $\mathrm{KOH}$ là $3 \mathrm{M}$ và nồng độ dung dịch IPA là $1 \mathrm{M}$ ) phủ màng bạc dày 20 nm (Hình 6) cho thấy, các hạt nano bạc (AgNPs) có dạng hình câu, kích thước khoảng 20 - 30 nm với khoảng cách giữa các hạt khoảng 15 - 25 nm, mật độ các hạt AgNPs dày, phân bố đồng đêu trên toàn bộ kim tự tháp và ở các khe dưới chân. Kết quả này cho thấy các thông số chế tạo của quá trình phún xạ được nêu ở mục 2.2.2 là tối ưu.
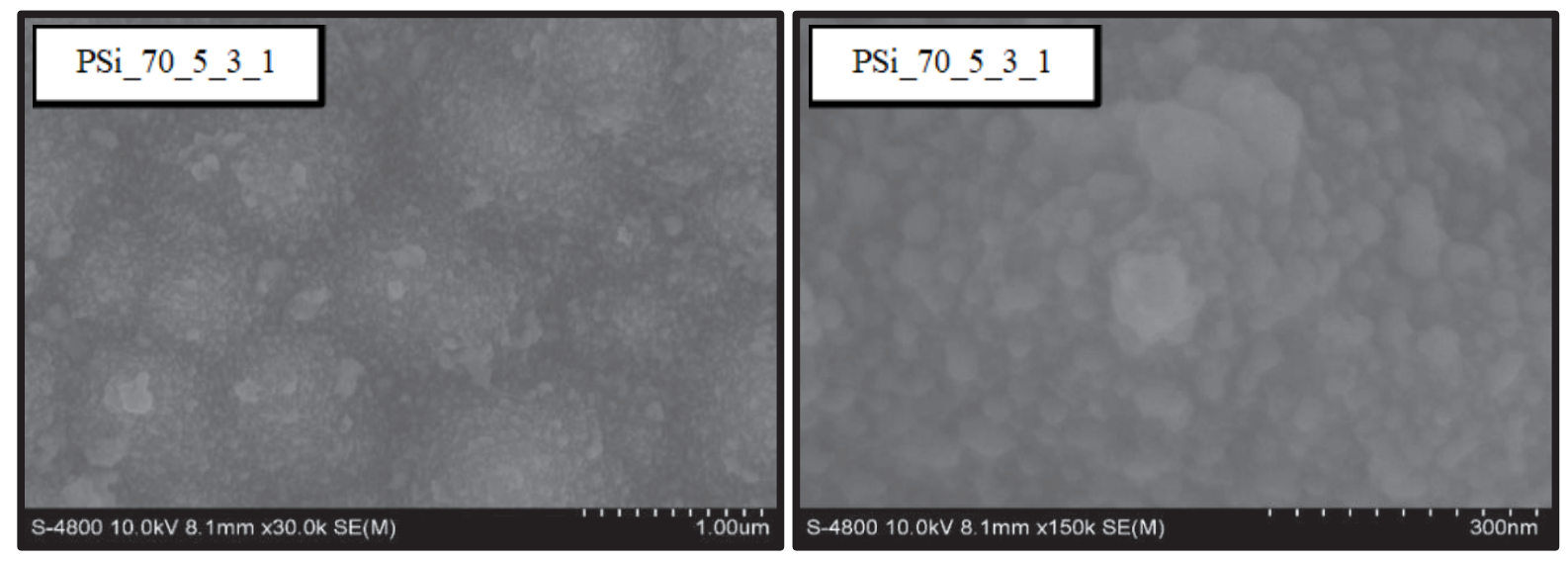

Hình 6. Ảnh SEM của mẫu PSi_70_5_3_1 phủ màng bạc dày $20 \mathrm{~nm}$ ở thang do $100 \mathrm{~nm}$ và $300 \mathrm{~nm}$

Giản đồ nhiễu xạ XRD của Si wafer, PSi và Ag@PSi (hình 7a) đều xuất hiện đỉnh đặc trưng của Si (100) ở góc $2 \theta=69.25^{\circ}$. Điều này cho thấy sau quá trình tạo đế PSi và tạo lớp phủ nano bạc thì vẫn không làm thay đổi cấu trúc của tinh thể Si ban đâu. Đối với giản đô nhiễu xạ XRD của mẫu Ag@PSi thấy rằng có sự xuất hiện của 03 đỉnh nhiễu xạ ở các vị trí đặc trưng với $2 \theta$ là $38.2^{\circ}, 44.3^{\circ}, 64.5^{\circ}$ lân lượt tương ứng với các họ mặt mạng (111), (200), (220) (Hình 7b). Bên cạnh đó, đỉnh nhiễu xạ tương ứng với mặt mạng (111) có cường độ mạnh nhất hay nói cách khác là hướng ưu tiên mọc tinh thể trong trường hợp này là hướng (111). Kết quả này đã chứng tỏ sự có mặt của Ag trên các đế PSi. 


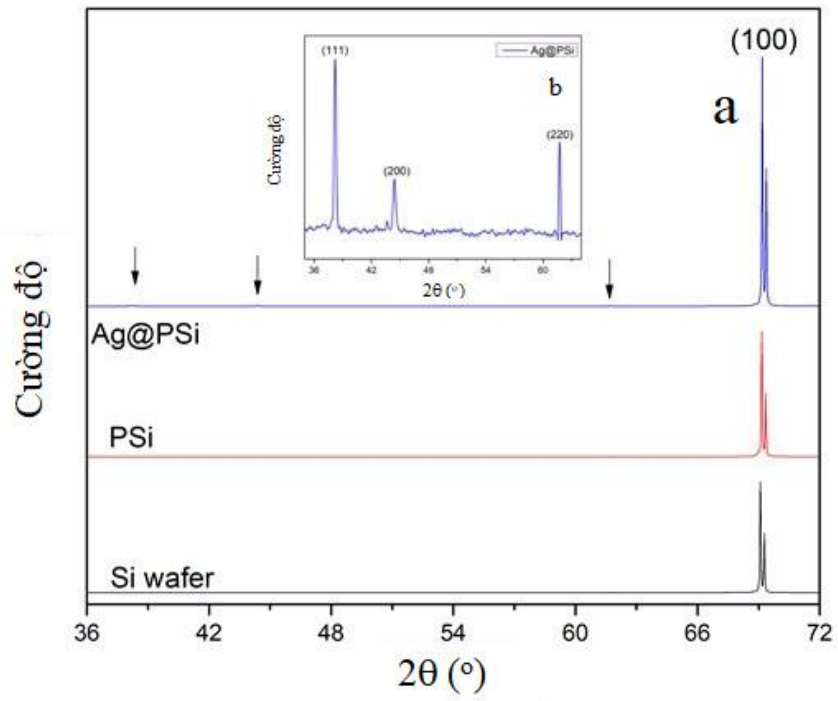

Hình 7. Giản đồ XRD của Si wafer, PSi và Ag@PSi (a) và giản đồ XRD của Ag@PSi được phóng to ở góc $2 \theta$ tü $36^{\circ}$ dến 65 (b)

\section{3. Đánh giá khả năng tăng cường tín hiệu Raman (SERS) của đế Ag@PSi}

Để khảo sát khả năng tăng cường tín hiệu tán xạ bề mặt của $\mathrm{Ag} @ P S i$, nhóm nghiên cứu tiến hành đo SERS với chất phân tích R6G với các nồng độ thay đổi từ $5 \times 10^{-4} \mathrm{M}$ đến $10^{-6} \mathrm{M}$. Kết quả cho thấy, tất cả các phổ (Hình 8a) đều xuất hiện đỉnh đặc trưng của Si wafer ở $519 \mathrm{~cm}^{-1}$ và các đỉnh đặc trưng của $\mathrm{R} 6 \mathrm{G}$ trong vùng $600-1.700 \mathrm{~cm}^{-1}$ bao gồm: đỉnh tại $612 \mathrm{~cm}^{-1}$ là dao động biến dạng trong mặt phẳng C-C-C; các đỉnh tại $774 \mathrm{~cm}^{-1}$ và $1.181 \mathrm{~cm}^{-1}$ tương ứng với dao động biến dạng của liên kết C-H ngoài mặt phẳng và trong mặt phẳng; các đỉnh tại $1.362 \mathrm{~cm}^{-1}$, $1.510 \mathrm{~cm}^{-1}$ và $1.651 \mathrm{~cm}^{-1}$ là dao động kéo dãn của liên kết $\mathrm{C}-\mathrm{C}$ và đỉnh tại $1.310 \mathrm{~cm}^{-1}$ là dao động kéo dãn của $\mathrm{C}-\mathrm{N}$. Đông thời, khi nông độ $\mathrm{R} 6 \mathrm{G}$ giảm từ $5 \cdot 10^{-4} \mathrm{M}$ đến $10^{-6} \mathrm{M}$ thì cường độ các đỉnh đặc trưng R6G giảm. Từ dữ liệu phổ Raman của các mẫu, chúng tôi tiến hành xây dựng đường chuẩn của cường độ đỉnh ở số sóng $1.362 \mathrm{~cm}^{-1}$ theo nông độ $\mathrm{R} 6 \mathrm{G}$ và kết quả được thể hiện ở Hình $8 \mathrm{~b}$. Trong khoảng nồng độ $5 \cdot 10^{-4} \mathrm{M}$ đến $10^{-6} \mathrm{M}$, đường tuyến tính có hệ số tương quan $\mathrm{R}^{2}=0,96$. Như vậy, nhóm nghiên cứu đã thành công trong việc chế tạo được đế SERS có khả năng phát hiện R6G ở nồng độ thấp $\left(10^{-6} \mathrm{M}\right)$.
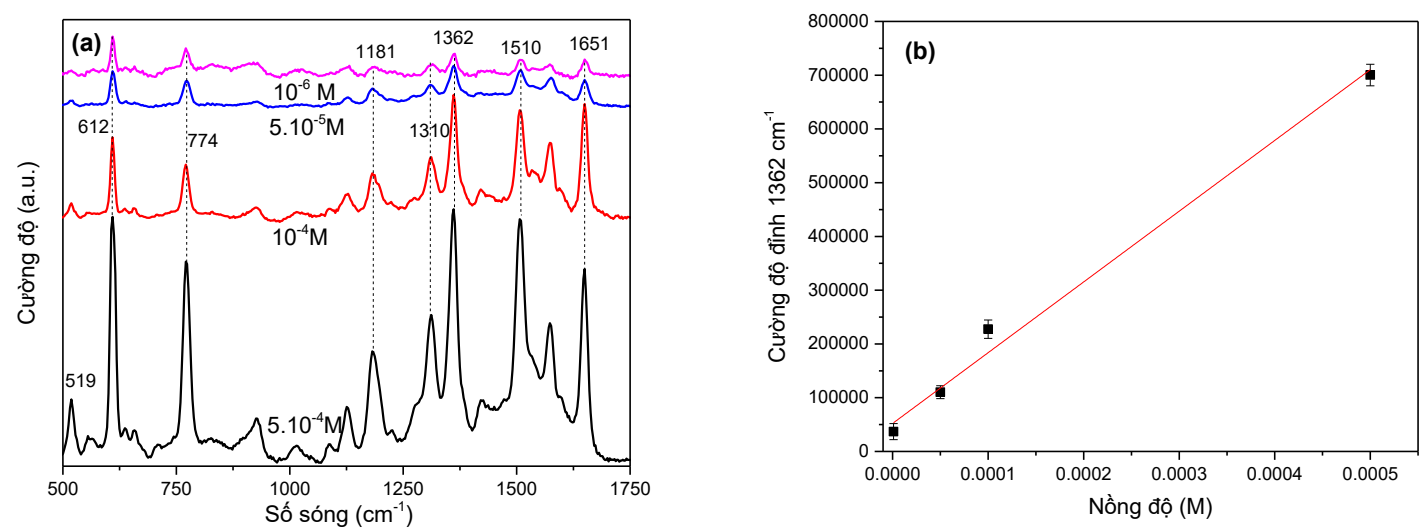

Hình 8. Phổ SERS của R6G với các nông độ khác nhau trên đế Ag@PSi (a) và đường fit cuiơng độ đỉnh $1.362 \mathrm{~cm}^{-1}$ theo nông độ R6G (b) 


\subsection{Hệ số tăng cường tín hiệu $(\mathrm{EF})$ của đế $\mathrm{Ag} @ \mathrm{PSi}$}

Để đánh giá khả năng tăng cường tín hiệu Raman đóng góp bởi cấu trúc kim tự tháp của đế Silic từ dữ liệu Raman của đế $\mathrm{Ag} @ \mathrm{PSi}$ so với đế của $\mathrm{Ag}$ trên $\mathrm{Si}$ phẳng chưa có cấu trúc kim tự tháp (đế thông thường $\mathrm{Ag} @ \mathrm{Si}$ ), chúng tôi đã tính hệ số tăng cường $(\mathrm{EF})$ tại đỉnh $1.362 \mathrm{~cm}^{-1}$ dựa vào công thức (1):

$$
E F=\frac{I_{A g @ P S i} \cdot N_{S i}}{I_{S i} \cdot N_{A g @ P S i}}
$$

Trong đó, $\mathrm{I}_{\mathrm{Ag} @ \mathrm{PSi}}$ và IAg@S lần lượt là cường độ đỉnh phổ đặc trưng của chất được hấp phụ trên đế $\mathrm{SERS}$ và đế thông thường; $\mathrm{N}_{\mathrm{Ag} @ \mathrm{Si}}$ và $\mathrm{N}_{\mathrm{Ag} @ \mathrm{PSi}}$ là số phân tử trong thể tích tán xạ của phép đo Raman trên đế $(\mathrm{Si})$ và phép đo $\mathrm{SERS}$. Hình 9 thể hiện phổ Raman của R6G trên đế $\mathrm{Ag} @ \mathrm{Si}$ và $\mathrm{Ag} @ \mathrm{PSi}$ ở các nồng độ tương ứng là $10^{-3} \mathrm{M}$ và $10^{-6} \mathrm{M}$.

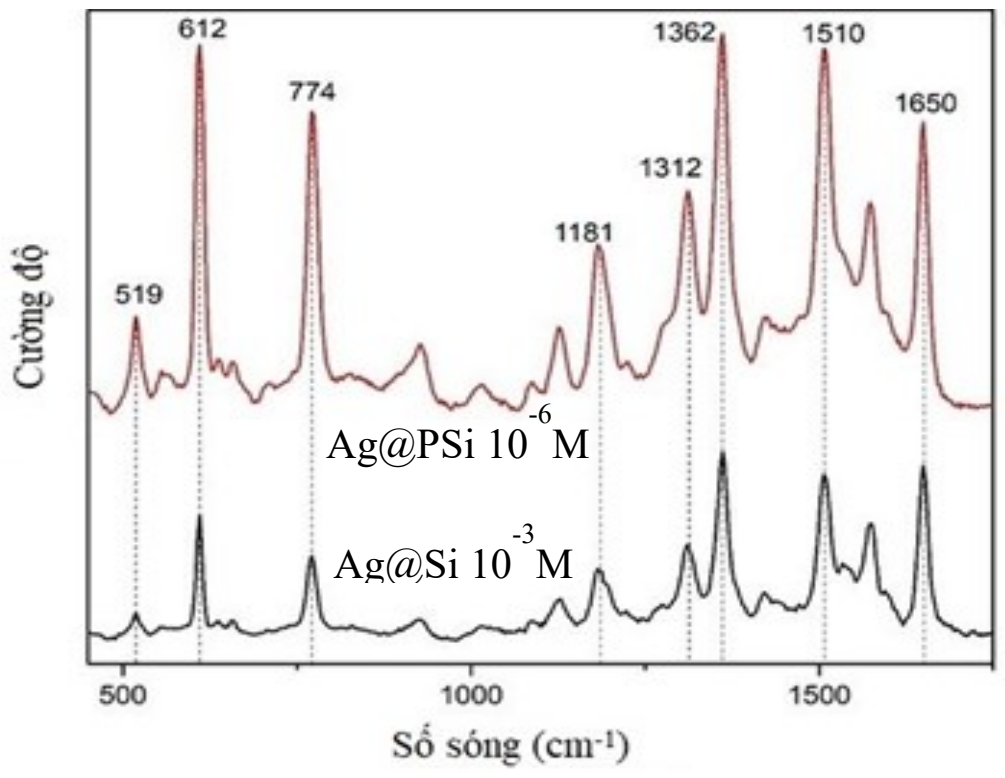

Hình 9.Phổ SERS của R6G trên đếAg@Si và Ag@PSi.

Kết quả tính được hệ số tăng cường $\mathrm{EF}$ tại đỉnh phổ đặc trưng của R6G $1362 \mathrm{~cm}-1$ là 9,7 $\times 10^{2}$. Điều này chứng tỏ các đế $\mathrm{Ag} @ \mathrm{PSi}$ có khả năng phát hiện R6G ở nồng độ thấp và cấu trúc kim tự tháp của Silic tăng cường tín hiệu tán xạ của đế SERS Ag@PSi lên khoảng $10^{3}$ lần.

\section{KẾT LUẬN}

Nghiên cứu đã chế tạo thành công đế Silic có cấu trúc kim tự tháp đồng nhất trên bề mặt, kích thước từ $1-3 \mu \mathrm{m}$ với các thông số tối ưu là nhiệt độ ăn mòn ở $70^{\circ} \mathrm{C}$, thời gian ăn mòn là 5 phút, nông độ dung dịch $\mathrm{KOH}$ là $3 \mathrm{M}$ và nồng độ dung dịch IPA là $1 \mathrm{M}$. Đông thời, chúng tôi đã tạo được lớp phủ hạt nano bạc có bề dày $20 \mathrm{~nm}$ lên đế Silic cấu trúc kim tự tháp bằng phương pháp phún xạ và cho hiệu ứng tăng cường tín hiệu Raman với dung dịch R6G ở nông độ thấp $\left(10^{-6} \mathrm{M}\right)$ và cấu trúc kim tự tháp đã tăng cường tín hiệu Raman lên $9,7 \times 10^{2}$ lần.

\section{LỜI CẢM ƠN}

Nghiên cứu này được tài trợ bởi Trường Đại học Khoa học Tự nhiên - Đại học Quốc gia Thành phố Hồ Chí Minh, với mã số đề tài T2019 - 37. 


\section{TÀI LIẸU THAM KHẢO}

[1]. B. Sharma, R. R.Frontiera, A. I. Henry, E. Ringe and R. P.Van Duyne, "SERS: Materials, applications, and the future," Materials Today, vol. 15, no. 1-2, pp. 16-25, 2012.

[2]. I. Rigo, M. Veres, L. Himics, S. Toth, A. Czitrovszky, A. Nagy and P. Furjes, "Comparative analysis of SERS substrates of different morphology," Procedia Engineering, vol. 168, pp. 371-374, 2016.

[3]. A. M. Al-Husseini and B. Lahlouh, "Silicon pyramid structure as a reflectivity reduction mechanism," Journal of Applied Sciences, vol. 17, pp. 374-383, 2017.

[4]. L. Sun, P. Chen and L. Lin, "Enhanced molecular spectroscopy via localized surface plasmon resonance," Intech, 2016.

[5]. M. Kahraman, E. R. Mullen, A. Korkmaz and S. Wachsmann-Hogiu, "Fundamentals and applications of SERS-based bioanalytical sensing," Nanophotonics, vol. 6, no. 5, 2017.

[6]. R. Nisticò, P. Rivolo, C. Novara and F. Giorgis, "Newbranched flower-like Ag nanostructures for SERS analysis," Colloids and Surfaces A, vol. 578, 2019.

[7]. S. Jiang, J. Guo, C. Zhang, C. Li, M. Wang, Z. Li, S. Gao, P. Chen, H. Si and S. Xu, "A sensitive, uniform, reproducible and stable SERS substrate has been presented based on MoS2@Ag nanoparticles@pyramidal silicon," RSC Advances, vol. 7,pp. 5764-5773, 2017.

[8]. Z. Li, S. C. Xu, C. Zhang, X. Y. Liu, S. S. Gao, L. T. Hu, J. Guo, Y. Ma, S. Z. Jiang and H. P. Si, "High-performance SERS substrate based on hybrid structure of graphene oxide/AgNPs/ Cu film@pyramid Si," Scientific Reports, 2016.

[9]. A. Roy, A. Maiti, T. K. Chini and B. Satpati, "Annealing Induced Morphology of Silver Nanoparticles on Pyramidal Silicon Surface and Their Application to Surface Enhanced Raman Scattering," ACS Applied Materials and Interfaces, vol. 9, no. 39, 2017.

[10]. I. T. Sugiarto, Isnaeni and K. Y. Putri, "Analysis of dual peak emission from Rhodamine 6G organic dyes using photoluminescence," Journal of Physics: Conference Series, vol. 817, 2017.

[11]. C. Zhang, S. Z. Jiang, C. Yang, C. H. Li, Y. Y. Huo, X. Y. Liu, A. H. Liu, Q. Wei, S. S. Gao, X. G. Gao and B. Y. Man, "Gold@silver bimetal nanoparticles/pyramidal silicon 3D substrate with high reproducibility for highperformance SERS," Scientific Reports, Article no. 6 : 25243, 2016.

[12]. N. Ximello, H. Haverkamp and G. Hahn, "A new KOH-etch solution to produce a random pyramid texture on monocrystalline silicon at elevated process temperatures and shortened process times," Materials Science, pp. 1958 - 1960, 2009.

[13]. I. Zubel, K. Rola and M. Kramkowska, "The effect of isopropyl alcohol concentration on the etching process of Si-subtrates in $\mathrm{KOH}$ solutions," Sensors and Actuators A Physical, vol. 171, no. 2, pp. 436-445, 2011.

[14]. Y. Wang, R. Luo, J. Ma and S. Q. Man, "Fabrication of the pyramidad microstructure on silicon substrate using $\mathrm{KOH}$ solution", The 5th International Conference on Advanced Engineering Materials and Technology, AEMT 2015, pp. 302-307, 2015. 


\title{
Fabrication and study of Raman signal enhancement of pyramid/ nano-Ag structured Silic substrate
}

\author{
Dau Tran Anh Nguyet ${ }^{1,2}$, Van Vo Kim Hieu ${ }^{1,2}$ \\ Tran Thi Thanh Van ${ }^{1,2}$, Huynh Nguyen Thanh Luan ${ }^{1,2}$ \\ ${ }^{1}$ Faculty of Material Science and Technology, University of Science, VNU-HCM, Vietnam \\ ${ }^{2}$ Vietnam National University Ho Chi Minh City
}

\section{Abstract}

The pyramid-structured silicon substrate was successfully fabricated by a chemical corrosion method with an average thickness of about $1-3 \mu \mathrm{m}$ with the optimal parameters such as corrosion temperature of $70^{\circ} \mathrm{C}$, corrosion time of $5 \mathrm{~min}$, concentration $\mathrm{KOH}$ of $3 \mathrm{M}$ and isopropyl alcohol concentration of $1 \mathrm{M}$. After that, the silver nanoparticles layer (thickness 20 $\mathrm{nm}$ ) was coated on the silicon substrate by a sputtering method to enhance the SERS signal. The results proved that the Pyramid/nano Ag structure silicon substrate showed the enhancement effect of Raman signal, and Rhodamine 6G pigment in food at low concentration $\left(10^{-6} \mathrm{M}\right)$ was detected and the enhancement factor was $9.7 \times 10^{2}$.

Keywords: Ag@PSi, PSi, Raman, SERS, Silic substrate. 